\title{
Por que ler hoje $A$ destruição da razão?
}

\author{
Ana Selva Albinati* \\ LUKÁCS. A destruição da razão. Tradução de Bernard Herman Hess, Rainer Patriota, \\ Ronaldo Vielmi Fortes; revisão de Ester Vaisman, Ronaldo Vielmi Fortes. São Paulo: \\ Instituto Lukács, 2020, 794p.
}

"Despreza a razão e a ciência, as mais excelsas forças do homem, e eu te terei inteiro sob meu poder."

(Goethe)

O livro $A$ destruição da razão, em sua primeira publicação em português, é fruto do empenho do Instituto Lukács, com tradução de Rainer Patriota, Bernard Herman Hess e Ronaldo Vielmi Fortes e revisão técnica de Ester Vaisman e Ronaldo Vielmi Fortes. O primeiro ponto a se ressaltar é a ousadia de tal publicação, certamente a obra mais polêmica de György Lukács. Maior ousadia se encontra no fato de que tal publicação se dê em um momento ainda mais hostil à reflexão ali contida, o que só a torna mais oportuna e necessária: tempo em que o irracionalismo se espraia em suas expressões mais vulgares e de forma mais disseminada e que coincide, tristemente, com 0 desmembramento do Arquivo Lukács em Budapeste e com a abreviação brusca das atividades do próprio Instituto Lukács em Maceió, dadas as condições adversas que rodeiam o pensamento crítico.

$A$ destruição da razão foi publicada originalmente em 1954 e apresenta o esforço do autor em compreender a ambiência teóricocultural que se desenvolveu a partir de meados do século XIX na Alemanha e que culminou na ideologia fascista. $O$ livro rememora criticamente a trajetória e o lugar do irracionalismo, em suas diversas expressões, na constituição e no fortalecimento dessa ambiência, se oferece como elemento de reflexão e alerta para pensar o tempo presente - os anos 50 vividos por Lukács -, e o nosso próprio tempo.

Lukács examina o pensamento de diversos autores e correntes da filosofia, da sociologia e da economia, tentando demonstrar a razão de ser de conceitos e representações ali defendidos em virtude do momento históricosocial no qual se encontram e ao qual respondem. Acompanha as diversas fases do desenvolvimento do irracionalismo, desde sua primeira expressão em Schelling, e de forma mais explícita nas críticas de Schopenhauer e Kierkegaard a Hegel, estendendo sua investigação aos períodos subsequentes, quando da formação e disseminação do fascismo. A tese lukácsiana é que os fundamentos filosóficos de pensadores dessa quadra histórica alemã, tais como o questionamento da possibilidade da razão de alcançar a verdade, a aporia entre entendimento e razão, a negação da historicidade, a consideração da intuição como base para o conhecimento e a ênfase na vivência como contraposição à objetividade que em si já constituem um ideário reacionário, na medida em que, como afirma Lukács, representam respostas reativas à situação concreta do desenvolvimento alemão acabaram por ser instrumentalizados pelos ideólogos alinhados propriamente ao nacionalsocialismo, amplificando-se assim em uma atmosfera cultural favorável ao fascismo.

Trata-se, fundamentalmente, do esclarecimento da gênese social do pensamento - com o que se nega a autonomia das expressões ideais em relação à sua base histórico-econômica -, e do lugar do intelectual

\footnotetext{
* Doutora em filosofia pela UFMG e professora do departamento de filosofia da Pontifícia Universidade Católica de Minas Gerais.
} 
como responsável por sua leitura do mundo. Em suas palavras: "Todo pensador é, nesse sentido, responsável diante da história pelo conteúdo objetivo de sua filosofia" (LUKÁCS, 2020, p. 10).

Isso não significa, como ele adverte, que os autores examinados fossem nazistas, ou protonazistas, mas sim que suas posições filosóficas terminam por consolidar a possibilidade de uma ideologia nazista, na medida em que essa ideologia se apropria do clima irracionalista, sentimental, negador da razão e da ciência, que deixa espaço para a criação de mitos e a manipulação arbitrária de ideias e conceitos. $O$ seu objetivo é "desmascarar todos aqueles trabalhos teóricos que prepararam o terreno para a visão de mundo nacional-socialista, mesmo que eles estejam - aparentemente - muito distantes do hitlerismo ou que - subjetivamente - estejam distantes de tais intenções" (LUKÁCS, 2020, p. 10).

Sua preocupação está voltada para o fato de que tais proposições filosóficas terminam por escapar dos gabinetes, infiltrando-se no senso comum e dando suporte a uma determinada visão de mundo. Clara está aqui a sua própria compreensão, a ser explicitada em sua Ontologia do ser social, da ideologia em seu sentido ontoprático: a ideologia como um instrumento de conscientização (a despeito de sua correção ou falsidade) que atua no comportamento dos indivíduos em seu posicionamento frente a conflitos sociais. E clara é também a percepção acerca dos processos manipulatórios já disponíveis naquele momento nos meios de comunicação que tornam essa disseminação mais eficiente, atingindo as massas. Assim, ao se referir a Hitler, ele aponta como nele se misturam filosofia da vida alemã e técnica publicitária norte-americana, ambas expressões relacionadas ao desenvolvimento do capitalismo monopolista.

Lukács nos mostra como na trajetória da filosofia alemã, Hegel representa o ápice da compreensão do mundo moderno em seu momento ascensional da burguesia revolucionária, e, como após Hegel, ocorre uma repartição de sua herança que, em termos bastante sintéticos, constitui uma encruzilhada. De um lado, a crítica materialista de Marx que retira os aspectos mistificadores do pensamento hegeliano resultantes da inversão ontológica entre ser e predicado, reposicionando assim a dialética em sua imanência como lógica do objeto. Tal apropriação crítica, como diz Marx em O Capital, transforma a dialética de moda em horror para a burguesia porque pensa as possibilidades históricas a partir das contradições.

Do outro lado, é essa dialética e a própria historicidade que são negadas, segundo Lukács, pelas correntes irracionalistas. São correntes que respondem de forma reacionária às possibilidades efetivas do evolver histórico naquele momento, contribuindo assim, consciente ou inconscientemente, para a manutenção de um fim da história que coincide com a sociabilidade burguesa, cujas mazelas são naturalizadas, como em Schopenhauer ou Nietzsche, ou podem ser minimizadas por uma afirmação da subjetividade, abstratamente autonomizada em relação à objetividade hostil, como se verifica na filosofia da vida e na filosofia da existência, que, com matizes diferentes, operam sobre contraposições de caráter imediatista, tais como vida autênticavida ordinária, temporalidade verdadeiratemporalidade ordinária, ou ainda, transpostas ao plano sociológico, na contraposição culturacivilização. Todas essas contraposições, retiradas do plano sensível-imediato da vivência, têm em comum a desconsideração da dialética entre totalidade e elemento, de forma a encerrar a reflexão num plano abstrato que separa e recusa a relação entre esfera econômica e a totalidade social. Não por acaso, Lukács inicia o seu livro com o estudo das características do desenvolvimento alemão, caracterizado por Lenin como via prussiana, via que conjuga $o$ atraso social e político com 0 desenvolvimento econômico iniciado tardiamente, mas de forma acelerada, a ponto de lançar a Alemanha na disputa imperialista em meio às nações europeias mais avançadas. É nesse contexto específico que se pode compreender o irracionalismo alemão, na sua negação da historicidade e do progresso, bem como na crença de um papel regenerador da cultura por parte da Alemanha.

Hegel é tido por Lukács como um divisor de águas na medida em que a crítica ao seu pensamento levou à bifurcação entre uma crítica ontológica que busca repor adequadamente suas conquistas, expostas de forma mistificada, e uma crítica irracionalista que abomina exatamente o que há de mais rico na compreensão hegeliana da realidade: a processualidade histórico-dialética. A natureza teórica dessa segunda crítica a Hegel é o que Lukács tentará demonstrar em seu livro de 1954 que, como nos lembra Tertulian, $^{1}$ tem como contrapartida positiva o texto $O$ jovem Hegel e os problemas da sociedade capitalista, publicado originalmente em 1948. Lukács

\footnotetext{
${ }^{1}$ TERTULIAN, N. A destruição da razão 30 anos depois. Verinotio, n. 13, ano VII, abr./2011, pp.15-25.
} 
observa que, embora o termo "irracionalismo" não faça parte da dicção hegeliana, em sua Fenomenologia do espírito, o filósofo critica o saber imediato, a intuição como acesso direto ao conhecimento e o sentimento como base insegura para a apreensão da realidade, na medida em que tais elementos levam à arbitrariedade e permitem o relativismo. Esses elementos que Hegel já criticava em Schelling e no romantismo em geral são germinais no desenvolvimento de posturas que, ao recusarem a superação dos limites do entendimento por via dialética, terminam por tentar transpor a aporia entre o sensível e o inteligível através do apelo ao suprarracional, ao misticismo e da superposição da possibilidade acima da realidade.

Lukács examina o percurso de meados do século XIX a meados do século XX, identificando as fases específicas do desenvolvimento alemão em seus aspectos econômicos, sociais, políticos e culturais, e apontando a emergência dos conceitos que acompanham essas fases. Da contraposição inicial ao racionalismo hegeliano ao desenvolvimento de teses que aprofundam o irracionalismo, o autor captura a relação da "ideologia alemã" com o momento em que se colocam definitivamente em cena as contradições do capitalismo, com o processo de unificação da Alemanha e a necessidade alemã de inserção imperialista, qualificando-a como uma apologia indireta ao capitalismo monopolista.

Posteriormente, a situação alemã após a derrota da primeira guerra, a insatisfação com a democracia de Weimar, sobretudo após a crise de 29, os descaminhos dos movimentos dos trabalhadores, já apontados pelas críticas de Marx e Engels aos programas de Gotha e de Erfurt, o sentimento de desespero e falta de expectativa, formam a situação ideal para a germinação de ideias que se descolam da objetividade e propõem saltos redentores. Alcança-se com isso uma psicologia de massas que conjuga desespero ideológico e concretude da vida cuja expressão anímica, uma vez publicitariamente trabalhada, potencializa os elementos contidos na filosofia da vida rumo à ação. A proposição lukácsiana é dura: "Hitler e Rosenberg levaram para as ruas tudo que foi dito sobre o pessimismo irracionalista desde Nietzsche e Dilthey até Heidegger e Jaspers em confortáveis poltronas de couro, em salões intelectuais e cafés" (LUKÁCS, 2020, p. 78).

O acompanhamento desse percurso nos permite compreender como foram possíveis as manifestações mais autoritárias, brutas e funestas, que respondem às necessidades de desenvolvimento do capitalismo, mas que só puderam se dar sob determinada cobertura ideológica. É a esse ponto que Lukács se refere ao dizer que, se costumamos perguntar como o povo aderiu ao fascismo, a questão mais curiosa a se pensar é como pensadores cultos aderiram aos mitos e profecias de Schopenhauer e Nietzsche.

Um pensamento se torna ideologia quando, sob circunstâncias concretas, ele leva à ação prática. Relembrando Marx, as doutrinas não saíram do livro para a realidade, mas da realidade para o livro. O problema é quando essa realidade é retratada equivocadamente, presa apenas às vivências e às impressões mais imediatas, e criando assim abstrações nada razoáveis. Lukács diz que esse fenômeno se dá em épocas de declínio de uma velha ordem social e possibilidade de outra. Mas essa outra precisa ser vislumbrada, sob pena de ser asfixiada no delírio social do irracionalismo. Uma apologia indireta do capitalismo se apresenta na medida em que essa possibilidade é obscurecida, e se convertem os horrores do capitalismo em horrores da existência em geral, como faz Schopenhauer, ou em desafios para a emergência do além do homem, como propõe Nietzsche. Pessimismo imobilizador ou heroísmo subjetivo que têm em comum o aristocratismo diante da plebe.

Em Kierkegaard, a contraposição a Hegel se dá pela construção de uma pseudodialética subjetiva qualitativa na qual "a qualidade nova surge com a subitaneidade do enigmático" (KIERKEGAARD apud LUKÁCS, p. 226). O que significa a emergência do novo sem relação com a objetividade, a possibilidade do salto, do milagre, da redenção, por sobre a realidade. Lukács compreende tal postura a partir do acirramento das contradições sociais que forçou a filosofia a tomar posição e o filósofo a expor o que entende por realidade. Esta é dialética ou não? $\mathrm{Na}$ definição do irracionalismo está presente não apenas um rebaixamento da capacidade da razão, mas a recusa da razão dialética, o aprisionamento ao entendimento e ao enrijecimento que cancela as possibilidades superadoras dos problemas sociais, agora assumidos como condição humano-social. Por isso, o irracionalismo é sempre reacionário. Ele surge sobre a base da produção capitalista e suas lutas de classe e atua na negação da possibilidade de sua superação. Nesse fenômeno ocorre a separação da filosofia em relação ao desenvolvimento científico, o que abre as portas para a arbitrariedade. Esse desprendimento da objetividade, por seu turno, leva a vivência do desespero ao encontro de uma visão de mundo de caráter subjetivista. Daí a adesão espontânea de vasto contingente de pessoas a formulações advindas das filosofias da vida e da existência, ainda que sem clareza de suas implicações.

Lukács identifica a diferença entre a filosofia 
da vida e a filosofia da existência que se desenvolve a partir de Heidegger e Jaspers. Enquanto a primeira busca a conquista do mundo objetivo pela subjetividade (afirmação da vontade de potência em vista de uma atmosfera anímica de desespero e falta de sentido), na segunda, a existência passa a ser o oposto da vida, expressa a angústia diante do tornar-se inessencial da vida em geral e se caracteriza por uma negação passiva da vida ordinária. Enquanto a filosofia da vida dividia os indivíduos em tipos (como em Nietzsche), na filosofia da existência essa cisão se dá na própria individualidade e busca preservar a autenticidade da subjetividade. Assim compreende Lukács que em Heidegger "os escritos se referem aos estados de alma provocados pela crise do capitalismo imperialista do pós-guerra", são "reflexos anímicos da realidade econômico-social" (LUKÁCS, 2020, p. 438). O problema está em que tal filosofia só considera os reflexos subjetivos e, abstraindo a subjetividade da realidade objetiva, introduz uma divisão artificiosa entre uma história real imprópria e a historicidade, entre um tempo real vulgar e a temporalidade autêntica, entre o ser decaído e o ser para a morte. Lukács considera Heidegger, assim como Jaspers, como precursores do irracionalismo fascista, na medida em que naturalizam essa atmosfera anímica da qual falam. No caso de Heidegger, acresce-se o fato de que ele se coloca no interior de um movimento teórico pela renovação cultural do Ocidente a ser protagonizada pela Alemanha, tema caro ao nazismo. Desses autores ao retorno à filosofia da vida, no talhe propriamente pré-fascista e fascista, com Klages, Junger, Baeumler, Boehm, Krieck e Rosenberg, é uma questão de vulgarização das teses irracionalistas para as massas e criação de elementos que levem à mobilização desse potencial anímico pessimista no sentido de uma política expansionista que se vale, dentre outros pretextos, do conceito de raça e do mito da raça ariana.

O autor continua a exposição das correntes filosóficas àquele momento tratando da recepção do pensamento de Hegel pelos neohegelianos após a primeira guerra, tais como Kroner, Glockner ou Dilthey, como autores que afirmam o irracionalismo de Hegel, aproximando-o de Schopenhauer ou da filosofia da vida. Sobre essa questão, o livro anterior de Lukács, O jovem Hegel, é primoroso na crítica a essas leituras deturpadoras.

Há ainda um capítulo a respeito da nascente sociologia como ciência particular, sobre a qual recai a crítica de estabelecer uma suposta independência das questões sociais em relação às questões econômicas. Esclarece Lukács que o surgimento da sociologia se dá quando do fim da economia clássica, que levou ao materialismo histórico e à crítica da economia política por um lado, e à economia vulgar por outro. $O$ tratamento das questões sociais abstraídas das questões econômicas constitui um falseamento da realidade social, um desmembramento conveniente na medida em que a raiz da questão social é separada de seus efeitos, de forma a deslocar os problemas sociais para os campos ético, jurídico e político. Uma ilustração desse procedimento se encontra em Ferdinand Töennis, no qual se encontra a crítica romântica à sociedade identificada com o capitalismo: "Sua postura constitui o fundamento de uma crítica da cultura em que se destacam os traços problemáticos e negativos da cultura capitalista, ao mesmo tempo que se sublinha, de modo fatalista, a inevitabilidade do capitalismo" (LUKÁCS, 2020, p. 516).

Sobre Max Weber e Simmel, Lukács dirá de uma introdução na sociologia burguesa de formas abstratas de interação entre base e superestrutura que buscam, fundamentalmente, suplantar a teoria da acumulação originária. Também aqui o autor aponta uma inversão na compreensão da origem e desenvolvimento do capitalismo que se baseia em fenômenos superficiais que assumem o papel determinante em relação aos problemas do desenvolvimento capitalista, levando ao demasiado dimensionamento das formas ideológicas como a religião e o direito. É tentador arriscar que $A$ destruição da razão seja $A$ ldeologia alemã de Lukács, no sentido de que aqui se encontra o acerto de contas com seu pensamento do início do século, quando de sua inserção no círculo Weber de Heidelberg, assim como seu propósito, tal qual o de Marx e Engels, seja identificar a relação entre pensamento e mundo.

Acompanhando as nuances das tendências no interior da sociologia, Lukács trata dos autores da sociologia liberal e da sociologia pré-fascista e fascista, que trazem à cena o darwinismo social e a teoria das raças, expressões contundentes do uso deturpado e manipulatório das ciências biológicas com propósitos de mobilização da insatisfação das massas, dirigida agora para um determinado alvo. Do ponto de vista teórico, o darwinismo social responde à necessidade de uma nova apologética do capitalismo que, não podendo mais negar os seus aspectos nocivos, passa a afirmar a sua naturalidade e eternidade, desembocando em um malthusianismo cósmico.

De uma forma geral, o livro é grandioso em sua pretensão e na riqueza de conteúdo. Em aspectos específicos, tem-se que a perspectiva de leitura lukácsiana, remetendo os pensadores examinados à sua inserção social e 
identificando-os, em sua generalidade, como respostas reacionárias ao movimento dos trabalhadores e à possibilidade revolucionária, abre espaço para a crítica dos leitores simpáticos a tais autores, em geral atentos apenas à letra, mas não ao espírito dos textos. No entanto, a severidade da abordagem de Lukács tem sua razão de ser comprovada a partir de apreciações tais como a de Rosenberg, franco ideólogo do nazismo, para quem o nacional-socialismo "só reconhece como seus verdadeiros antecessores Richard Wagner, Nietzsche, Lagarde e Chamberlain" (LUKÁCS,
2020, p. 622). Embora mais sofisticada, a base filosófica examinada por Lukács, pode ser vulgarizada pelo nacional-socialismo porque tem em comum "o desvio da objetividade, o apelo unilateral aos sentimentos, às vivências" (LUKÁCS, 2020, p. 632), e dessa forma, pode parecer uma resposta acessível aos indivíduos presos em sua particularidade, disseminandose pela capilaridade da vida cotidiana. É esse o alerta que nos traz Lukács e é por isso que a leitura de $A$ destruição da razão mantém a sua importância e urgência no tempo presente.

\section{Como citar:}

ALBINATI, Ana Selva. Por que ler hoje $A$ destruição da razão?. Verinotio, Rio das Ostras, v. 27, n. 1, pp. 452-456, jan./jun 2021. 